\title{
Earth's climate response to a changing Sun
}

Coordinated by: Jean Lilensten, Thierry Dudok de Wit, Katja Matthes

Editors: Thierry Dudok de Wit, Ilaria Ermolli, Margit Haberreiter, Harry Kambezidis, Mai Mai Lam, Jean Lilensten, Katja Matthes, Irina Mironova, Hauke Schmidt, Annika Seppälä, Eija Tanskanen, Kleareti Tourpali, Yoav Yair 
COST (European Cooperation in Science and Technology) is a pan-European intergovernmental framework. Its mission is to enable break-through scientific and technological developments leading to new concepts and products and thereby contribute to strengthening Europe's research and innovation capacities. It allows researchers, engineers and scholars to jointly develop their own ideas and take new initiatives across all fields of science and technology, while promoting multi- and interdisciplinary approaches. COST aims at fostering a better integration of less research intensive countries to the knowledge hubs of the European Research Area. The COST Association, an International not-for-profit Association under Belgian Law, integrates all management, governing and administrative 10 functions necessary for the operation of the framework. The COST Association has currently 36 Member Countries.

http: //www. cost.eu/

COST is supported by the EU Framework Programme Horizon 2020

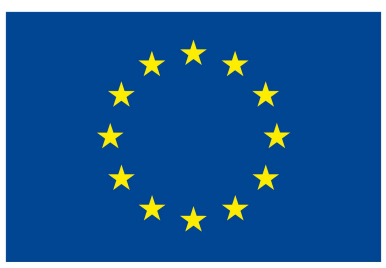

Cover illustration: Sunset observed from the International Space Station - expedition 15 (NASA). Aurora at Svalbard, by Cyril Simon Wedlund (Aalto-University (Finland) and IPAG-CNRS).

Printed in France

ISBN: 978-2-7598-1733-7

DOI: $10.1051 / 978-2-7598-1733-7$

This work is subject to copyright. All rights are reserved, whether the whole or part of the material is concerned, specifically the rights of translation, reprinting, re-use of illustrations, recitation, broad-casting, reproduction on microfilms or in other ways, and storage in data bank. Duplication of this publication or parts thereof is only permitted under the provisions of the French Copyright law of March 11, 1957. Violations fall under the prosecution act of the French Copyright law.

(c) EDP Science, 2015 